\title{
Hyperammonaemia Due to Ornithine Transcarbamylase Deficiency
}

\author{
IAN J. HOPKINS, JOHN F. CONNELLY, A. G. DAWSON, F. J. R. HIRD, AND \\ T. G. MADDISON \\ From the Department of Paediatrics, and the Russell Grimwade School of Biochemistry, \\ University of Melbourne, and the Royal Children's Hospital, Melbourne, Victoria, Australia
}

Accumulation of ammonia in body tissues most commonly occurs in hepatic failure. However, it may also result from a specific deficiency of an enzyme of the urea cycle (Fig. 1). Severe hyperammonaemia has been reported with deficiencies of carbamyl phosphate synthetase (Freeman et al., 1964) and ornithine transcarbamylase (Russell et al., 1962; Levin and Russell, 1967). Some increase in blood ammonia also occurs in citrullinaemia due to lack of argininosuccinate synthetase

\section{UREA CYCLE AND ASSOCIATED PATHWAYS}

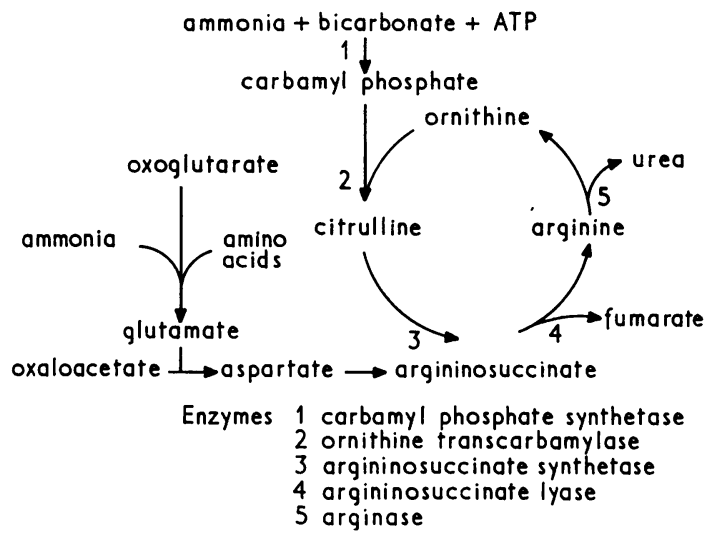

FIG. 1.-The Krebs-Hensleit urea cycle. The numbers refer to the enzymes listed and deficiency of any of these enzymes is associated with hyperammonaemia.

(McMurray et al., 1963) and in argininosuccinic aciduria due to argininosuccinate lyase deficiency (Westall, 1960). Primary arginase deficiency has not been described; but competitive inhibition of this enzyme by lysine has been postulated to

Received July 24, 1968. explain the high blood ammonia levels in congenital lysine intolerance (Colombo et al., 1964). Rett (1966) has reported hyperammonaemia in a group of 21 mentally retarded girls, but the cause of the high blood ammonia in these patients is unknown.

This paper describes a further instance of hyperammonaemia due to ornithine transcarbamylase deficiency. This case demonstrates some previously undescribed clinical features and a favourable response to dietary protein restriction. However, a fatal outcome associated with ammonia intoxication followed laparotomy and liver biopsy.

\section{Case Report}

First admission. The patient (Fig. 2), a Caucasian female infant, was referred at 10 months of age for investigation of vomiting, irritability, and slow development. She was the first child of unrelated Australian parents and was conceived after several years of infertility. The pregnancy was normal except for possible rubella contact at 3 months' gestation. No abnormalities were noted during labour, delivery, or in the neonatal period. Birthweight was $3.25 \mathrm{~kg}$. Physical growth and motor milestones were considered normal until she was 7 months of age, but in retrospect smiling, noted at approximately 3 months, was delayed. Though somewhat floppy, she sat alone at 7 months and weighed $8.28 \mathrm{~kg}$. At this time she was weaned from the breast and given a variety of milk feedings. Thereafter her mother noticed increased irritability, floppiness, decreased alertness, frequent vomiting, and failure to gain weight.

At initial examination hypotonia was the outstanding feature. She weighed 7.77 kg. and her head circumference was $44 \mathrm{~cm}$. (third centile). Her face had a myopathic appearance and the tongue was large and protruberant. No other abnormalities were detected on examination of cranial nerves and the optic fundi were normal. There was moderately severe hypotonia of trunk and limb muscles, with diminished spontaneous movement. Deep tendon reflexes were within normal limits. Soft smooth enlargement of the liver to $4 \mathrm{~cm}$. 

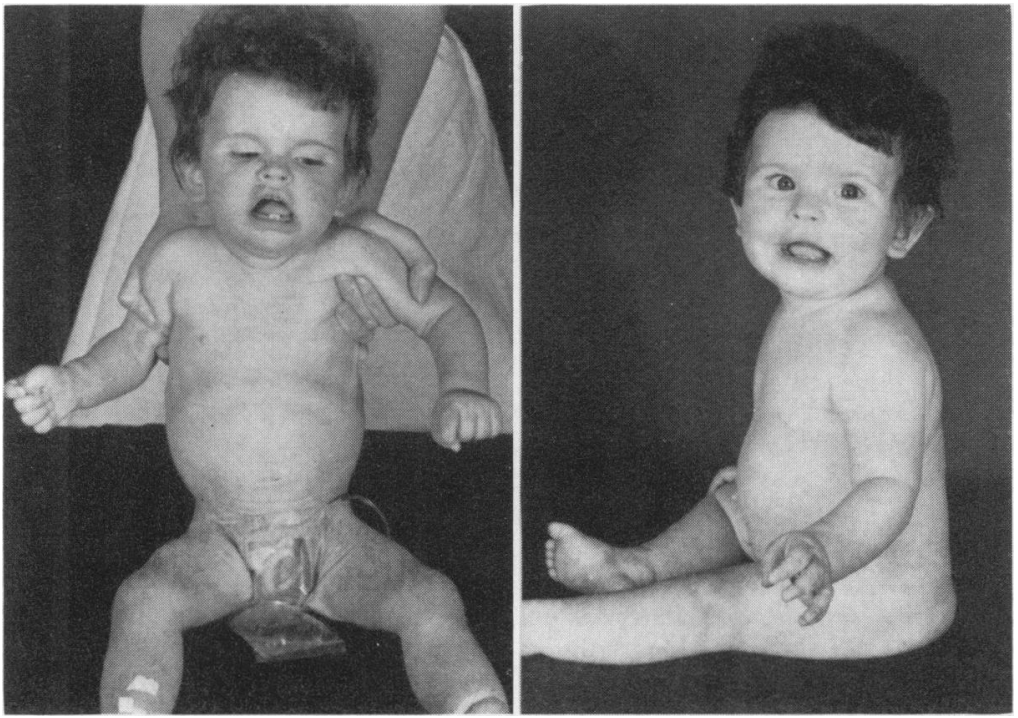

Fig. 2.-(a) Patient at 13 months, showing poor nutrition and wasted quadriceps. (b) At 17 months, after 3 months of dietary treatment, she was well nourished and able to sit alone.

below the right costal margin was the only other clinical abnormality.

Investigations with normal results at this time included haemoglobin, white cell count, ESR, chest and abdomen $x$-rays, EEG, EMG, serum sodium, potassium, chloride, calcium, phenylalanine, proteinbound iodine, $\mathrm{T}_{3}$ resin uptake, and CSF examination for cells, protein, and sugar. Her blood urea was 19 mg. $/ 100 \mathrm{ml}$., and there was a mild respiratory alkalosis $\left(p \mathrm{H} 7.48, \mathrm{PCO}_{2} 27 \mathrm{~mm}\right.$. $\mathrm{Hg}$, base excess $0 \mathrm{mEq} / \mathrm{l}$.). Urine chromatography showed an increase in glutamine and glutamic acid; citrulline and argininosuccinic acids were not detected. Barium meal examination showed free oesophageal reflux, and intravenous pyelography and micturating cystourethrography revealed mild ureteric reflux. The bone-marrow was hypocellular, but there was no evidence of tumour or lipoid storage cells. She was discharged without adequate diagnosis.

Second admission. When aged 13 months she was readmitted with similar symptoms; her weight had fallen to $6.72 \mathrm{~kg}$., and muscle wasting, especially of the quadriceps, was prominent (Fig. 2a). During the next two weeks she was listless, vomited intermittently, and lost more weight. Because of this a high protein diet was started, but she then became extremely restless. Rapid deterioration in level of consciousness followed and she became deeply comatose over a period of 24 hours. At this time hypertonia developed, contrasting with previous hypotonia. Tendon reflexes remained brisk. Multifocal clonic twitching of the extremities was noted, particularly on the right side. Fontanelle tension remained normal, but optic disc swelling developed. The liver was enlarged $6 \mathrm{~cm}$. below the right costal margin. Respirations were gasping, and she appeared moribund. Intravenous therapy was begun and over the next few days depth of coma diminished and rigidity was replaced by hypotonia. Within three days she responded to pain and within a week was moving spontaneously. Truncal ataxia was prominent at this stage. However, she did not appear to recognize her parents or to focus or follow visually. When oral feeding was started again there was a second period of restlessness and screaming.

At this time blood ammonia estimations (Hyland Blood Ammonia Test 030-020) showed strikingly increased values of $430 \mu \mathrm{g} . / 100 \mathrm{ml}$. on one occasion and $730 \mu \mathrm{g} . / 100 \mathrm{ml}$. on another (normal less than 60 $\mu \mathrm{g} . / 100 \mathrm{ml}$.). Serum bilirubin was less than $0.5 \mathrm{mg} . /$ $100 \mathrm{ml}$., SGOT 110 SF units, SGPT 100 SF units, thymol turbidity 2 Maclagen units, serum proteins 5.9 g. $/ 100 \mathrm{ml}$., with a mild increase in $\alpha_{2}-$ and $\beta$ globulins, and bromsulphalein retention was less than $1 \%$ at 45 minutes. Repeated blood urea estimations were between 18 and $21 \mathrm{mg} . / 100 \mathrm{ml}$. Urine chromatography again showed increased glutamine and glutamic acid and there was also a slight increase in glycine. A sample of serum collected at this time and stored at $-20{ }^{\circ} \mathrm{C}$. was analysed several months later. This showed a moderate increase in glutamic acid and slight increase in lysine as the only abnormalities. Amino acid analysis of a sample of sweat (Hadorn et al., 1967) from the back showed a reduced level of citrulline. Pneumoencephalography showed mild to moderate generalized ventricular dilatation, especially of the 
third ventricle (width $10 \mathrm{~mm}$.) and temporal horns. An EEG showed marked diminution in amplitude of activity, with an almost flat recording interrupted at intervals by low voltage delta waves.

An 1100 calorie low protein diet $(1 \cdot 5 \mathrm{~g}$. protein $/ \mathrm{kg}$.) was then started and oral neomycin was given for 1 week. The blood ammonia fell over the next 2 weeks to $100 \mu \mathrm{g} . / 100 \mathrm{ml}$. where it remained for one month. The CSF ammonia was $210 \mu \mathrm{g} . / 100 \mathrm{ml}$. when the blood level was $225 \mu \mathrm{g} . / 100 \mathrm{ml}$. Over the next 2 months the blood ammonia concentration fell to $56 \mu \mathrm{g} . / 100 \mathrm{ml}$. by which time the CSF ammonia was $38 \mu \mathrm{g} . / 100 \mathrm{ml}$. and the blood urea $6 \mathrm{mg} . / 100 \mathrm{ml}$. Clinical improvement paralleled the falling ammonia levels and she rapidly gained weight, became more alert, and was no longer irritable. After 4 months of dietary treatment (Fig. 2b) she walked with only slight assistance. Vision and recognition of her parents returned after one month of treatment, but optic disc swelling remained for 6 weeks. The liver returned to normal size and liver function tests were normal except for slightly low serum protein of $5.5 \mathrm{~g} . / 100 \mathrm{ml}$. EEG showed a relatively normal pattern within a month of starting treatment.

Third admission. At 18 months she was admitted for elective open liver biopsy under general anaesthesia to study enzymes of the urea cycle. The biopsy was accomplished uneventfully and a sample of skin was also obtained. Her condition remained satisfactory for approximately 12 hours, but overnight she vomited copiously, and the following morning was dehydrated and comatose. At this time her blood ammonia was $1000 \mu \mathrm{g} . / 100 \mathrm{ml}$. compared with $72 \mu \mathrm{g} . / 100 \mathrm{ml}$. immediately after the biopsy procedure. Her blood urea had risen to $28 \mathrm{mg} . / 100 \mathrm{ml}$. Intravenous fluid replacement was started and assisted positive pressure ventilation was required because of respiratory depression. Multifocal convulsions were present. Treatment with anabolic steroids was begun. After a transient fall with rehydration, the blood ammonia rose to $1970 \mu \mathrm{g}$./ $100 \mathrm{ml}$. and 54 hours after operation peritoneal dialysis was begun. Details of temporary clinical improvement, associated with a considerable fall in blood ammonia, are described elsewhere in this journal (Herrin and McCredie, 1969). However, on the fifth post-operative day, blood pressure gradually declined, and after several cardiac arrests she died 5 days after operation. Optic disc swelling did not occur in the terminal phase. Except for some increase in $\mathrm{PCO}_{2}$ before and during the early phase of assisted ventilation, her acid base status was moderately well controlled and ketonuria was never detected. Serum electrolytes also remained within normal limits.

\section{Pathology}

The sample of liver obtained at biopsy showed moderately diffuse fatty change and accumulation of glycogen principally in centrilobular cells. Some halo nuclei were present. Very minor portal fibrosis, bile-duct proliferation, and sparse inflammatory infiltrate were also present.
At necropsy the liver weighed 485 g. (normal approximately 300 g.). Microscopically the appearances were similar to those seen at biopsy, though fatty change was more prominent and glycogen accummulation less. The pituitary gland was recently infarcted. The brain weighed $1265 \mathrm{~g}$. (normal approximately 950 g.), was extremely soft, and showed evidence of tentorial coning. Neurones of the cerebral cortex and basal ganglia showed chromatolysis. Many astrocytic nuclei were mildly enlarged (12-15 $\mu$ in diameter) and vacuolated. There was lysis of neurones of the cerebellar internal granular layer, and Purkinje and dentate neurones showed chromatolysis. No other significant abnormality was seen at necropsy.

\section{Enzyme Studies}

Activities of the urea cycle enzymes were measured on samples of liver and skin from the patient and a sample of liver from a control child. The control sample was obtained within an hour of death from an infant without liver disease. The liver specimens were extracted with $0.1 \%(\mathrm{~W} / \mathrm{V})$ cetyltrimethylammonium bromide, and enzymes were assayed in the extract by methods similar to those described by Brown and Cohen (1959). However, during preliminary studies, it was found that dilution of the extract, as recommended by Brown and Cohen, for assay of ornithine transcarbamylase and arginase led to considerable loss of enzyme activity. Therefore instead of using diluted extract, small volumes (10 to $100 \mu \mathrm{l}$.) of undiluted extract were introduced into the assay system by an Agla syringe. At least two samples of different volume were used for assay of each enzyme so that the amount of product to be estimated fell within the range of the method. Citrulline and urea were measured by the methods of Archibald (1944, 1945). Each enzyme was assayed at its optimum $p \mathrm{H}$, and, where this differs markedly from the average physiological value $(p H 7 \cdot 4)$, the enzyme activities recorded are probably higher than under physiological conditions. This difference has been shown to be most marked with arginase but also exists with ornithine transcarbamylase.

Results are shown in the Table. The outstanding finding was an extreme deficiency in ornithine transcarbamylase activity in the patient's liver, the activity

TABLE

Liver Urea Cycle Enzyme Activity

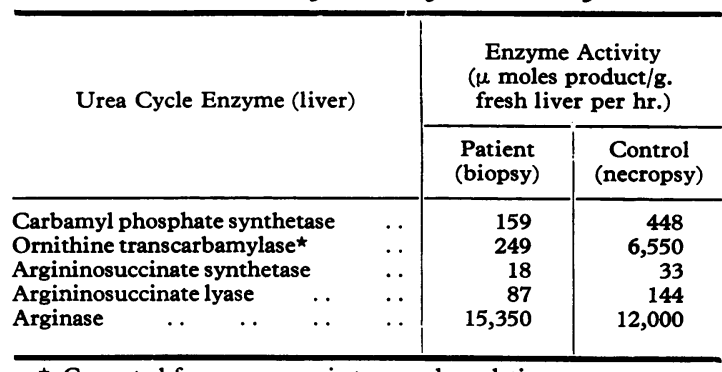

$\star$ Corrected for non-enzymic transcarbamylation. 
being less than $4 \%$ of the control. Carbamyl phosphate synthetase was reduced to less than $40 \%$ of the control. This assay depends on complete conversion of carbamyl phosphate produced to citrulline by ornithine transcarbamylase normally present in excess. As the patient's liver was deficient in ornithine transcarbamylase, partially purified enzyme from rat liver was added. In the absence of this supplement the apparent activity of carbamyl phosphate synthetase was reduced by a further one-third. Argininosuccinate synthetase and argininosuccinate lyase activities were also lower in the patient than in the control; arginase was slightly higher in the liver of the patient. In the patient's skin slight arginase activity was evident; activity of other enzymes of the urea cycle could not be shown.

\section{Discussion}

The evidence strongly suggests that this patient's illness resulted from hyperammonaemia due to deficiency of ornithine transcarbamylase, an enzyme of the urea cycle. The clinical and laboratory findings closely resemble those described by Russell et al. (1962). Certain aspects of the clinical course, ancillary investigations, treatment, and prognosis warrant further discussion.

Clinical features. Diagnosis of ammonia intoxication was first suspected when an association between severity of symptoms and protein content of the diet was appreciated. For the first six months when fed breast milk (protein content approximately $1.5 \mathrm{~g} . / 100 \mathrm{ml}$.) her development was relatively normal. After weaning and introduction of cows' milk of higher protein content (approximately $3.5 \mathrm{~g} . / 100 \mathrm{ml}$.) the clinical features of vomiting, irritability, floppiness, failure to thrive, and delay in milestones developed. Eventually introduction of a high protein diet led to further irritability, weight loss, hepatomegaly, and coma. When this diet was replaced by intravenous fluids during the period of coma she showed general improvement and this was maintained on a low protein diet.

Once suspected on clinical grounds, hyperammonaemia was confirmed, and the degree of increase in the blood ammonia is in itself noteworthy (Fig. 3). The initial values of 430 and $730 \mu \mathrm{g}$./ $100 \mathrm{ml}$. are higher than levels usually seen in hyperammonaemia due to hepatic failure and portosystemic encephalopathy. In the terminal episode after liver biopsy even greater increases occurred. Russell et al. (1962) also noted this extreme increase in blood ammonia. Though liver enlargement was present, relatively normal liver function tests suggested that hyperammonaemia in the present patient was not due to generalized liver disease. Enlargement of the liver has been reported in some cases of argininosuccinic aciduria (Efron, 1966) and in citrullinaemia (McMurray et al., 1963), and Freeman et al. (1964) described fatty change in the liver biopsy specimen from their patient with carbamyl phosphate synthetase deficiency. Return of the liver to normal size after restriction of dietary protein further suggested that hepatomegaly was not primary but secondary to ammonia intoxication.

An aspect of particular interest in relation to the effect of hyperammonaemia on nerve tissue was the optic disc swelling during the first period of coma. Persistence of impaired vision for several weeks after regaining consciousness and lack of evidence of raised intracranial pressure suggest this swelling was allied to optic neuritis rather than to papilloedema. Case A of Russell et al. (1962) with ornithine transcarbamylase deficiency also showed visual deterioration after the first six months of life, but the optic fundi were not described.

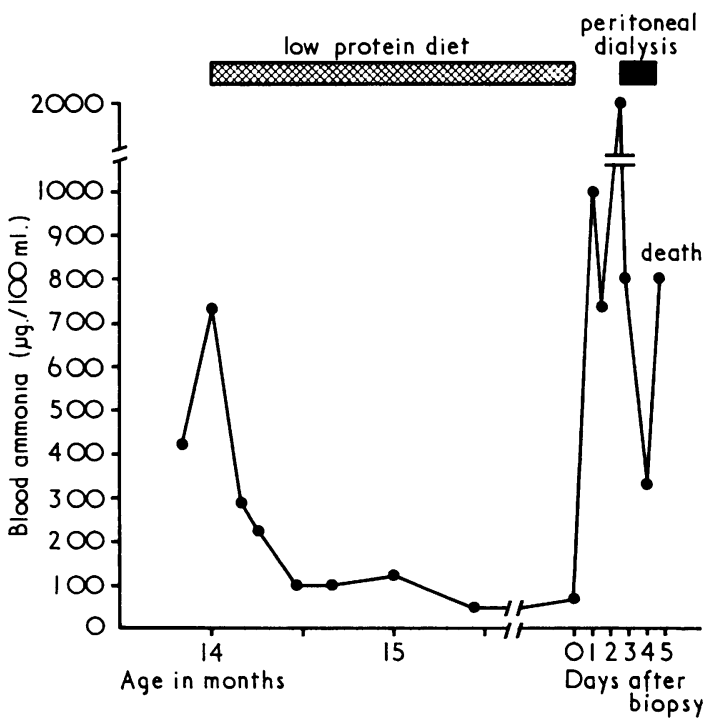

FIG. 3.-The marked hyperammonaemia that responded to dietary treatment is shown. The rapid and profound increase in blood ammonia after open liver biopsy and the fall with peritoneal dialysis is also illustrated.

Multifocal convulsive twitching was present in both episodes of coma. Though generalized convulsions have been reported in citrullinaemia, they were not described in the previously reported patients with ornithine transcarbamylase or carbamyl phosphate synthetase deficiency. However, Rett (1966) noted convulsions in 15 of the 21 patients he described with hyperammonaemia. 
Convulsions are not a feature of hyperammonaemia associated with liver failure and in the present case may be related to the very rapid rise in blood ammonia, or, alternatively, may reflect a different response in the immature brain. A more detailed discussion of features of special neurological interest, including serial electroencephalography and findings at pneumoencephalography, is presented elsewhere (Hopkins et al., 1968).

A most important clinical feature was the extreme vulnerability to a relatively minor surgical procedure. It appears that protein katabolism after surgery and anaesthesia was the basis for the profound hyperammonaemia that ensued. Case A of Russell et al. (1962) had an operative liver biopsy but no untoward complications were reported. Similarly liver biopsies have been successfully performed in patients with citrullinaemia and argininosuccinic aciduria. Death followed liver biopsy in the case of Freeman et al. (1964) with carbamyl phosphate synthetase deficiency, but was associated with severe ketosis, and hyperammonaemia was not reported in the terminal episode. Ketosis was never observed after operation in our patient.

Diagnosis of enzyme defect. It seems reasonable to attribute the hyperammonaemia in this patient to ornithine transcarbamylase deficiency ( $4 \%$ of the control value). The increased utilization of ammonia which occurred when purified ornithine transcarbamylase was added to the liver extract supports this interpretation. However, there was also some reduction in carbamyl phosphate synthetase, argininosuccinate synthetase, and argininosuccinate lyase to approximately $50 \%$ of activity in the control. Without further knowledge of the range of normal values, or of responses of the human to dietary and other factors, it is not possible to interpret the significance of the apparently decreased activities of enzymes other than ornithine transcarbamylase.

It is of interest that the blood urea was consistently between 18 and $21 \mathrm{mg} . / 100 \mathrm{ml}$. before the low protein diet was started. This may be because no enzyme of the urea cycle was completely absent. In addition, some urea would be formed from arginine, either dietary or derived from protein katabolism. The increased urinary excretion of glutamic acid and glutamine can be explained by increased utilization of the following reactions in response to the increased accumulation of ammonia:

$\mathrm{NH}_{3}+2$-oxoglutarate $+\mathrm{NAD} \quad(\mathrm{P}) \mathrm{H}_{2} \rightleftharpoons$ glutamate

$\mathrm{NH}_{3}+$ glutamate $\rightarrow$ glutamine$$
+ \text { NAD }(P)
$$

However, on storage, glutamine tends to be converted to glutamic acid, and this may account for some of the increase in glutamic acid seen in the pretreatment serum and urine samples.

In some inborn errors of metabolism easily accessible tissues (blood, skin) can be used for enzyme analysis in diagnosis. Hadorn et al. (1967) studied amino acid levels in sweat from all parts of the body, and found a constant pattern except for amino acids of the urea cycle. This led them to support the suggestion of a urea cycle in sweat glands. As a sample of sweat from the present patient appeared to contain less citrulline than normal, assay of urea cycle enzymes on a skin biopsy was attempted. However, except for a very low arginase level no activities were demonstrated.

Treatment. Considerable improvement followed intravenous therapy and coincidental protein restriction during the first episode of coma, and this continued when a diet adequate in calories but restricted in protein was introduced. A short course of oral neomycin was given initially but was found unnecessary to control the blood ammonia level. The relatively dramatic improvement in neurological and mental deficits, which followed the low protein diet, contrasted with the situation seen in certain other metabolic disorders.

In spite of the gratifying response to the treatment of chronic ammonia intoxication, measures used in the terminal episode (gut sterilization, adequate hydration, anabolic steroids) had little effect while the patient was in the phase of postoperative protein katabolism. Peritoneal dialysis was effective in lowering the blood ammonia; however, the clinical response was short lived and hypoproteinaemia and oedema developed. Thus, though a promising temporary measure, further experience is required with peritoneal dialysis to assess its value in the treatment of hyperammonaemia. It is possible that earlier intervention with peritoneal dialysis might have been more successful. In the presence of ornithine transcarbamylase deficiency, it is possible that ammonia intoxication may be relieved by administration of citrulline. Under these conditions the ammonia produced from protein katabolism may follow the following pathway:

$$
\mathrm{NH}_{3} \rightarrow \text { glutamate } \rightarrow \text { asportate } \underbrace{\rightarrow}_{\text {citrulline }} \text { arginine } \rightarrow \text { urea + ornithine }
$$

It could be predicted that the administration of citrulline would lead to the accumulation of 
ornithine (mole for mole). The value of the treatment would thus depend on the relative toxicities of ammonia and ornithine. Such treatment was contemplated in the post-operative period but the patient died before it could be attempted. Other suggested means for controlling the ammonia levels in patients with hyperammonaemia are discussed by Levin and Russell (1967).

Prognosis. The encouraging response that followed dietary protein restriction in our patient suggests that reversal of motor and mental retardation can occur in hyperammonaemia, even when diagnosis is delayed. However, reports of other retarded patients with hyperammonaemia due to urea cycle defects are not so encouraging and more information is required. The long-term prognosis appears to be influenced by the potential susceptibility of these patients to stress, and it seems wise to avoid surgical procedures where possible and to guard against infection.

\section{Summary}

A case of hyperammonaemia in a female infant is described. Vomiting, irritability, regression in milestones, hypotonia, and hepatomegaly developed after weaning and introduction of a diet of higher protein content. Further increase in dietary protein to combat weight loss led to coma and convulsions. Once recognized, the hyperammonaemia responded to protein restriction and the patient showed clinical and neurological improvement. Assay of urea cycle enzymes on a liver sample, obtained at laparotomy under general anaesthesia, showed reduced ornithine transcarbamylase activity to $4 \%$ of that in a control sample. However, after operation, severe hyperammonaemia ensued and, despite temporary improvement with peritoneal dialysis, death occurred 5 days later. Thus, though some of the neurological features of hyperammonaemia appear to be reversible, prognosis should be guarded because of risk of severe hyperammonaemia in periods of protein katabolism.
We gratefully acknowledge the assistance of $\mathrm{Mr}$. John Hoban, St. Vincent's Hospital, Melbourne, for blood ammonia estimations, Mrs. B. Lynch for supervision of dietary treatment, Dr. Vivian Shih of Boston for amino acid estimation, and laboratory and nursing staff, and resident medical officers of the Royal Children's Hospital, particularly Dr. Bruce Hocking and Dr. John McNamara. Dr. John Herrin kindly carried out peritoneal dialyses.

\section{REFERENCES}

Archibald, R. M. (1944). Determination of citrulline and allantoin and demonstration of citrulline in blood plasma. $\mathcal{F}$. biol. Chem., 156, 121.

- (1945). Colorimetric determination of urea. ibid., 157, 507.

Brown, G. W., Jr., and Cohen, P. P. (1959). Comparative biochemistry of urea synthesis. f. biol. Chem., 234, 1769.

Colombo, J. P., Richterich, R, Donath, A., Spahr, A, and Rossi, E. (1964). Congenital lysine intolerance with periodic ammonia intoxication. Lancet, $1,1014$.

Efron, M. L. (1966). Diseases of urea cycle. In The Metabolic Basis of Inherited Disease, 2nd ed., p. 393. Ed. by J. B. Stanbury, J. B. Wyngaarden, and D. S. Fredrickson. McGraw-Hill, New York.

Freeman, J. N., Nicholson, J. F., Masland, W. S., Rowland, L. P., and Carter, S. (1964). Ammonia intoxication due to a congenital defect in urea synthesis. F. Pediat., 65, 1039.

Hadorn, B., Hanimann, F., Anders, P., Curtius, H. C., and Halverson, R. (1967). Free amino-acids in human sweat from different parts of the body. Nature (Lond.), 215, 416.

Herrin, J. T., and McCredie, D.A. (1969). Peritoneal dialysis in the reduction of blood ammonia levels in a case of hyperammonaemia. Arch. Dis. Childh., 44, 149.

Hopkins, I. J., Connelly, J. F., Hocking, B., and Maddison, T. G. (1968). Proceedings of the Australian Association of Neurologists, Vol. 5, Part 1, p. 183.

Levin, B., and Russell, A. (1967). Treatment of hyperammonemia. Amer. F. Dis. Child., 113, 142.

McMurray, W. C., Rathbun, J. C., Mohyuddin, F., and Koegler, S. J. (1963). Citrullinuria. Pediatrics, 32, 347.

Rett, A. (1966). Ueber ein zerebral-atrophisches Syndrom bei Hyperammonämie. Hollinck, Vienna. (Quoted by J. Lorber (1967). Develop. Med. Child Neurol., 9, 232.)

Russell, A., Levin, B., Oberholzer, V. G., and Sinclair, L. (1962). Hyperammonaemia. A new instance of an inborn enzymatic defect of the biosynthesis of urea. Lancet, 2, 699.

Westall, R. G. (1960). Argininosuccinic aciduria: identification and reactions of the abnormal metabolite in a newly described form of mental disease, with some preliminary metabolic studies. Biochem. F., 77, 135.

Correspondence to Dr. Ian J. Hopkins, Department of Neurology, Royal Children's Hospital, Flemington Road, Parkville, Melbourne, Victoria, 3052, Australia. 